\title{
Titanium-based thin films for protective coatings prepared by TVA (Thermionic Vacuum Arc) technology
}

\author{
R Vladoiu ${ }^{1}$, A Mandes ${ }^{1}$, V Dinca ${ }^{1}$, G Prodan ${ }^{1}$ \\ ${ }^{1}$ Ovidius University, Mamaia 124, Constanţa, 900527, Romania
}

\begin{abstract}
The aim of the present work is to achieve the controlled synthesis of $\mathrm{Ti}$ and $\mathrm{Mg}$ thin films, with compact structure and extremely smooth surface, by using the Thermionic Vacuum Arc (TVA) technology, from elemental powder of titanium and magnesium. The thin film exhibits an amorphous structure, with polycrystalline grain mainly being Mg hexagonal phase and small amount of hexagonal Ti. Grain mean size was estimated to be $\sim 120 \mathrm{~nm}$ by statistical analysis of measured Feret diameter of projected area of grain. The phases were tested by mean of Cohen method applied to electron diffraction results. No oxide $(\mathrm{MgO}, \mathrm{TiO} 2$,) lines could be identified from electron diffraction. Debye-Scherrer dimension, estimated from electron diffraction profile is $\sim 4 \mathrm{~nm}$. The analysis of amorphous part from diffraction profile show different coordination number for $\mathrm{Mg}$ and Ti atoms.
\end{abstract}

\section{Introduction}

Advanced materials at the nanometric scale started to be real dimensions for coating the components on production line. [1,3] Specifically, titanium based nanocomposites owing to their remarcable properties of the coating surfaces such as wear resistance, roughness, low friction coefficients have been synthetized and investigated in different combination and forms, such as multi-component composites. [4-7]

Titanium (Ti) is an ideal metal for structural and biomedical applications, having good biocompatibility, mechanical properties and high corrosion resistance. [811] By combining $\mathrm{Ti}$ and $\mathrm{Mg}$, the resulting $\mathrm{Ti}-\mathrm{Mg}$ alloys are expected to be useful as metallic biomaterials with good mechanical properties and anticorrosion properties. $[12,13]$. But, titanium cannot be dissolved in $\mathrm{Mg}$ under equilibrium conditions and so we need to use a deposition method that can produce single-phase, non-equilibrium Ti alloys in a wide composition range.

Magnesium is a rather strong, light-weight metal with two-thirds the density of aluminum. Its hygroscopic property- its ability to absorb water - makes it a great drying agent. Magnesium also contributes to an enhanced gripping resistance by its contact surface polishing action. However, because the wear resistance of magnesium products is not nearly as good as steel in ambient and high temperatures, there is a strong request to find a way that can guarantee better wear resistance in the aggressive atmosphere environment [14]. In general, surface treatments are used to improve the surface properties such as wear resistance and corrosion resistance.

When analyzing the mechanical properties of nanostructured metals, one should take into account the peculiar mechanisms of deformation, the role of the grain boundary phase, the mechanisms of grain boundary sliding and diffusional mass transfer. [15] One way to alter the grain size of the material in the controlled way is by using the co-deposition of two materials. Recently, the studies proved that the dependence of the behavior on the particle sizes can allow one to engineer their properties.

The challenge of this work is to find the best combination for coating the mechanical parts of components - especially those exposed to aggressive atmosphere environment - by suitable complex nanocomposites using innovative technology. Multicomponent thin films as well as single thin films were deposited using Thermionic Vacuum Arc (TVA) technology. TVA is a versatile deposition method combining anodic arc and electron gun systems for the growth of thin films. [16-18] In this paper we focused on the effects of $\mathrm{Mg}$ amount in the the titanium matrix, in terms of microstructural, morphological and mechanical properties.

\section{Experimental set-up}

The deposition of the Ti-Mg thin films was carried out by using the Thermionic Vacuum Arc (TVA) technology. The principle of TVA method consists in an intense thermal-electron emission from a circular external heated cathode (tungsten filament) focused on the anode (the crucible containing the material to be evaporated) by a Wehnelt cylinder. More details about this method can be find out elsewhere. [19-21] The outstanding features of this coating technique are: the high purity of the deposition, high ion and electron energies, and an 
adjustable degree of ionization of the involved species. The experimental set-up is shown in figure 1 .

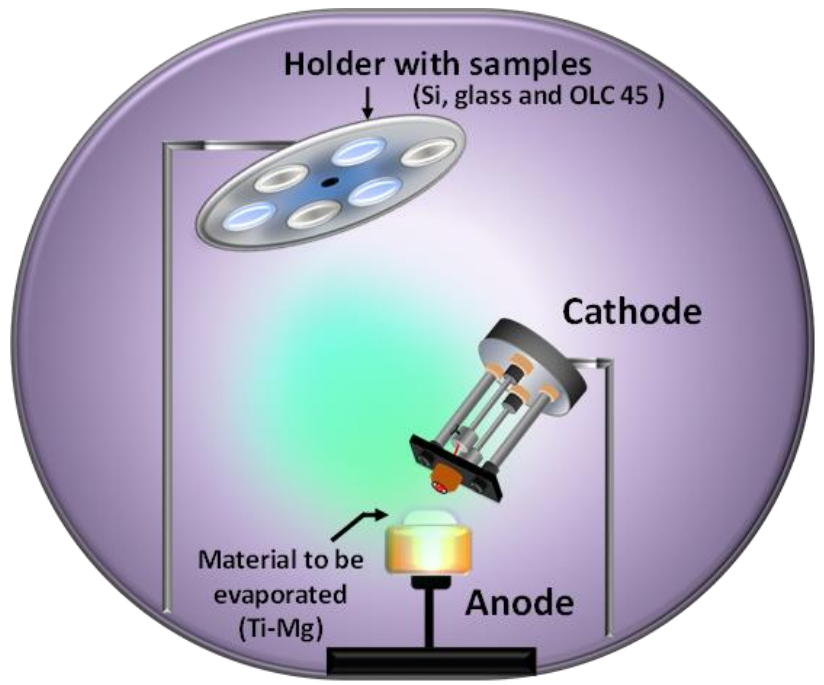

Figure 1 Schematical diagram of the experimental set-up

The working pressure during the deposition process was about $1.2 \times 10-5-5.5 \times 10-6$ Torr. The evaporation rate was stabilized and controlled with an accuracy of $10 \%$. Thickness measurements were performed in situ using a FTM 7 thickness monitor. The main experimental parameters involved in this study are presented in table 1 where:

- $\mathrm{I}_{\mathrm{f}}$ - the current intensity of the heating filament $\left(\mathrm{I}_{\mathrm{f}}=50 \mathrm{~A}\right)$;

- $\mathrm{I}_{\mathrm{a}}$ - the arc's current intensity $\left(\mathrm{I}_{\mathrm{a}}=16510^{-3} \mathrm{~A}\right)$;

- $\mathrm{U}_{\mathrm{a}}$ - the applied voltage $\left(\mathrm{U}_{\mathrm{a}}=0.7410^{3} \mathrm{~V}\right)$;

- $\mathrm{t}_{\mathrm{dep}}$ - the time of deposition $\left(\mathrm{t}_{\mathrm{dep}}=120 \mathrm{~s}\right)$;

- $\mathrm{d}_{\mathrm{a}-\mathrm{c}}$ the distance between anode and cathode $\left(\mathrm{d}_{\mathrm{a}-\mathrm{c}}=0.005 \mathrm{~m}\right)$;

- $d_{a-s^{-}}$the distance between samples and the point of the ignition of the discharge $\left(\mathrm{d}_{\mathrm{a}-\mathrm{s}}=0.16 \mathrm{~m}\right)$;

- $\varphi$ - the cathode-anode relative position between a perpendicular line on the crucible centre and the electron gun axis $\left(\varphi=45^{\circ}\right)$.

Table 1. Detailed experimental conditions for the magnesium nanocomposite

\begin{tabular}{|l|c|}
\hline Parameter & Value \\
\hline $\mathrm{I}_{\mathrm{f}}[\mathrm{A}]$ & 50 \\
\hline $\mathrm{I}_{\mathrm{a}} 10^{-3}[\mathrm{~A}]$ & 165 \\
\hline $\mathrm{U}_{\mathrm{a}} 10^{3}[\mathrm{~V}]$ & 0.74 \\
\hline $\mathrm{t}_{\mathrm{dep}}[\mathrm{s}]$ & 120 \\
\hline $\mathrm{d}_{\mathrm{a}-\mathrm{c}}[\mathrm{m}]$ & 0.005 \\
\hline $\mathrm{d}_{\mathrm{a}-\mathrm{s}}[\mathrm{m}]$ & 0.16 \\
\hline$\varphi\left[{ }^{0}\right]$ & 45 \\
\hline Deposition rate $[\AA / \mathrm{s}]$ & 3 \\
\hline
\end{tabular}

\begin{tabular}{llll}
$\mathbf{I}_{\mathbf{f}}[\mathbf{A}]$ & $\mathbf{I}_{\mathbf{a}} \mathbf{1 0}^{-3}[\mathbf{A}]$ & $\mathbf{U}_{\mathbf{a}} \mathbf{1 0}^{3}[\mathbf{V}]$ & $\mathbf{t}_{\text {dep }}[\mathbf{s}]$ \\
\hline 50 & 165 & 0.74 & 3600
\end{tabular}

\begin{tabular}{llll}
$\mathbf{d}_{\mathrm{a}-\mathrm{c}}[\mathbf{m}]$ & $\mathbf{d}_{\mathrm{a}-\mathrm{s}}[\mathbf{m}]$ & $\boldsymbol{\varphi}\left[{ }^{0}\right]$ & $\begin{array}{l}\text { Deposition } \\
\text { rate }[\AA / \mathbf{s}]\end{array}$ \\
\hline 0.005 & 0.16 & 45 & 3
\end{tabular}

Three types of substrates were used in this work: silicon wafer, OLC 45 (high-quality carbon steel with $45 \%$ C) and glass. Before the deposition, the substrates were chemically cleaned in ultrasonic bath with a highly effective special cleaner and then and then dried with cold air. The samples were mounted on the support and then inserted into the deposition chamber. After deposition the samples have been kept in the deposition chamber longer time after the power supplies were switch off, under high vacuum, in order to cool down the system temperature.

The samples were characterized using transmission electron microscope (TEM) accompanied with selected area electron diffraction (SAED) and scanning electron microscope (SEM). In addition, the tribological properties were studied by ball-on-disc tribometer made by CSM Switzerland in the dry regime.

\section{Results and discussions}

Scanning electron microscopy with energy dispersive Xray spectroscopy (SEM/EDX) is the most widely-used of the surface analytical techniques. SEM images were performed using a Zeiss EVO 50 SEM having LaB6 cathode with Bruker EDX system. EDX measurements were carried out with a Bruker accessory fitted on the Zeiss Evo 50 scanning electron microscope. The take-off angle is $35^{\circ}$ and the detector's resolution is $133 \mathrm{eV}$.

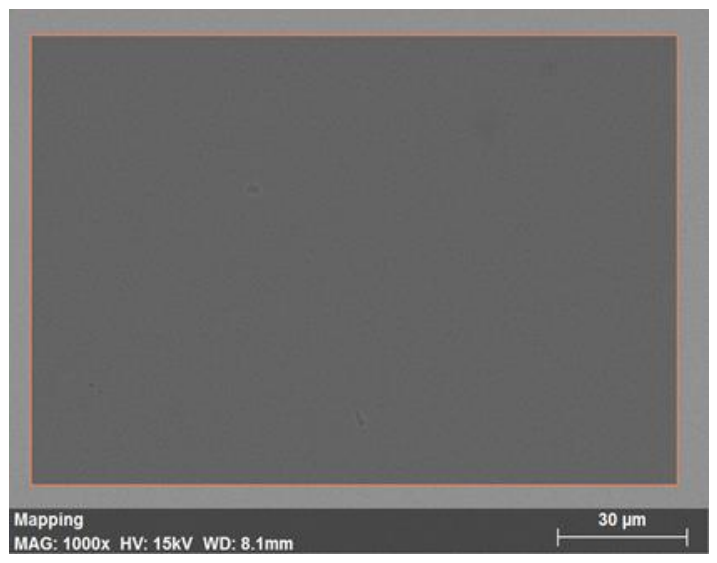

a) $\mathrm{Ti} \mathrm{Mg} / \mathrm{Si}$ 


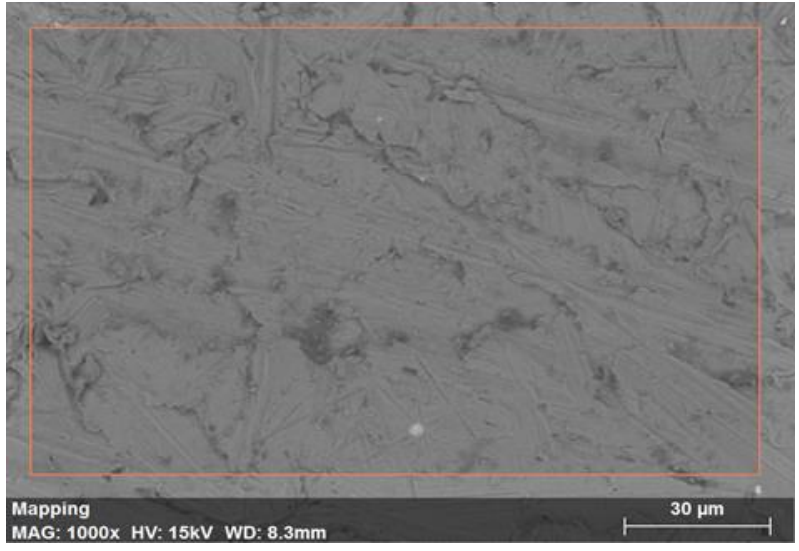

b) $\mathrm{Ti} \mathrm{Mg} / \mathrm{OLC}$

Figure 2 SEM micrographs of the Ti-Mg thin films

Scanning electron microscope (SEM) investigations revealed that the Ti-Mg thin films on each substrates were compact and uniform, while the average particle sizes of the nanoparticles composing the Ti-Mg thin films on different substrates are in range of $\sim 4 \mathrm{~nm}$ corresponding with the calculated particles achieved by the Scherrer equation.

The mean size (D) of the ordered (crystalline) domains, which may be smaller or equal to the grain size, was carried out by using Debye-Scherrer relation:

$$
\mathrm{D}=\mathrm{K} \lambda /(\beta \cos \theta)
$$

where $\mathrm{K}$ is the shape factor, $\lambda$ is the wavelength, $\beta$ is the line broadening at half the maximum intensity (FWHM) in radians, and $\theta$ is the Bragg angle.

Usually the dimensionless shape factor has a typical value of about 0.9 , but varies with the actual shape of the crystallite. Several factors can contribute to the width of a diffraction peak; besides crystallite size, the most important of these are usually inhomogeneous strain and instrumental effects. If we do not take into account these other contributions to the peak width, then the peak width would be determined solely by the crystallite size, in this case calculated as $3.2 \mathrm{~nm}$.

More information about the morphology and structure of the Ti-Mg thin films have been provided by Transmission Electron Microscopy (TEM) performed on a Phillips CM $120 \mathrm{ST}$ (acceleration voltage of $120 \mathrm{kV}$ ) TEM with a resolution point of $1.4 \AA$ and a magnification of 1.2 million times. For TEM investigation the samples were prepared using a diamond knife to scratch the surface of the film, with alcohol as a dispersive medium and a 400 $\mathrm{Cu}$ grid covered by formvar film as a holder for the sample. [22]

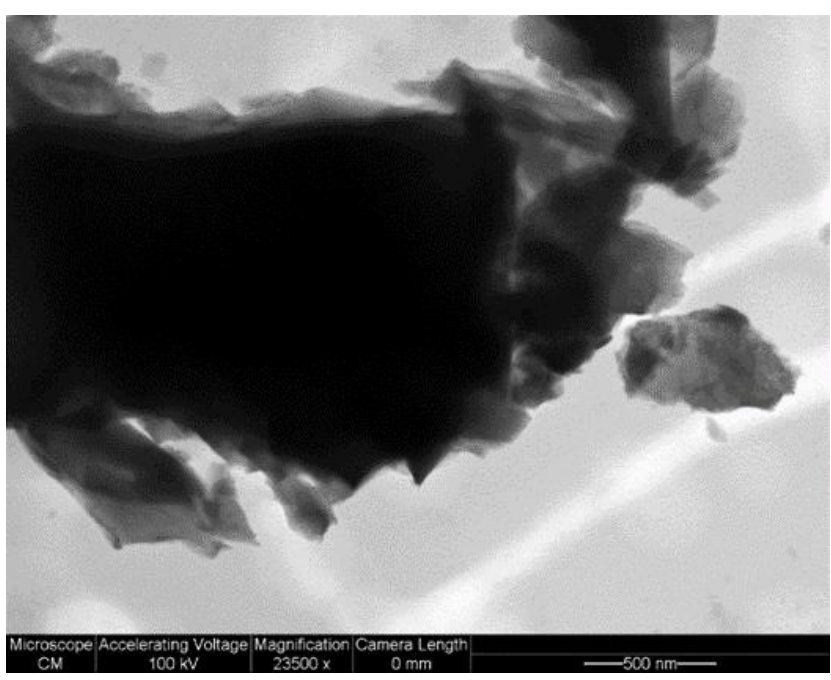

(a)

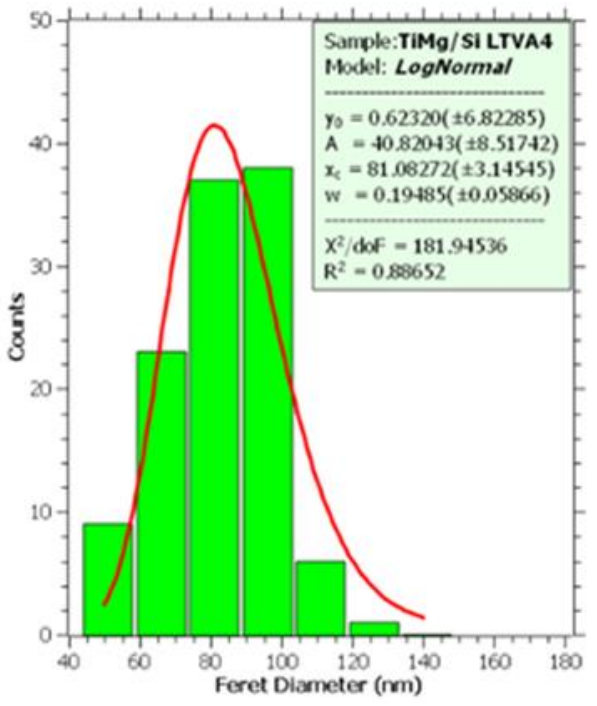

(b)

Figure 3 (a) HRTEM image of Mg-Ti /Si; (b) Grain size distribution

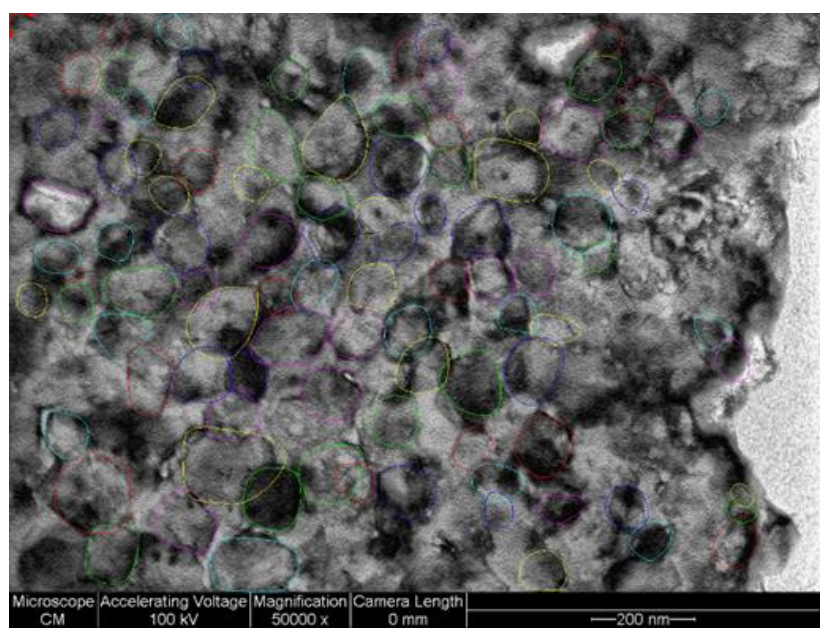

(a) 


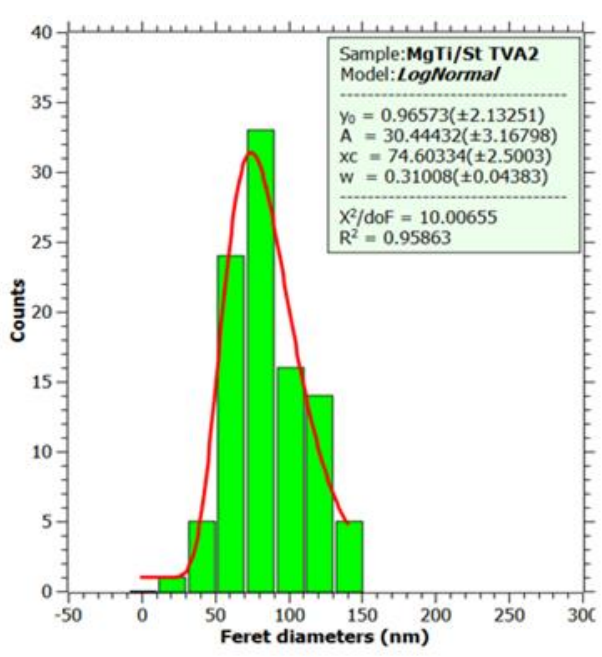

(b)

Figure 4 (a) HRTEM image of Mg-Ti/Gl; (b) Grain size distribution

TEM images at different resolutions (200 $\mathrm{nm}$ and $500 \mathrm{~nm}$ ) are shown in figure 3 and figure 4 and the grain size distribution using the Faret diameter estimate for the selected area in the image. The deposited thin films are nanostructured and the size of nanocrystaline structures according to Feret diameter is about $74 \mathrm{~nm}, 20 \mathrm{~nm}$ lower than the arithmetic mean of the determined values, which can be attributed to the small number of values used in the statistical analysis. The difference is within the range given by the standard deviation $( \pm 26.9 \mathrm{~nm})$.

For each sample, diffraction analysis was performed, using phase analysis to compare the known phases of the material, namely the Cohen method with the modified Nelson-Riley function for electron diffraction.

Figures 4 and 5 shows the diffraction patterns obtained, respectively the radial distribution profile and the peaks obtained using the ELD for polycrystalline materials implemented in the CRISP2 application. To identify the phases, we compared the peaks obtained from the measurements with known $\mathrm{Si}$ [23] and $\mathrm{Mg}$ [24] and $\mathrm{Ti}$ [25] respectively, and their oxides: $\mathrm{MgO}$ [26], and $\mathrm{TiO}$ [27].

For $\mathrm{Ti}-\mathrm{Mg}$ deposited on $\mathrm{Si}$ from the Debye-Scherrer analysis of the two profiles results a size of $1.7538 \mathrm{~nm}$ for the profile obtained on the amorphous film, respectively $5.8905 \mathrm{~nm}$ for the area leading to the formation of the polycrystalline diffraction pattern.

In Figure 5 and figure 6 are those patterns and related RDF. Profile analysis was made by means CRISP2 (ELD module) application. We use CRISP2 to extract and fit profile. The film is compound by nanoparticles very smoothly distributed, indicated by the presence of the well - defined rings by electron diffraction.

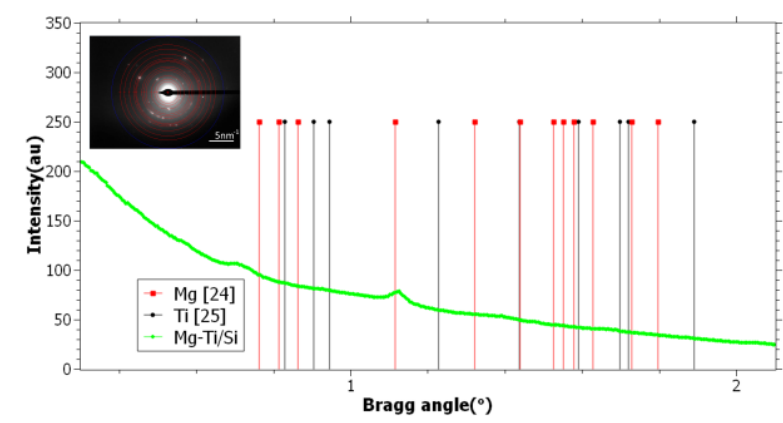

Figure 5 RDF functions extracted by means of CRISP2 ELD module for $\mathrm{Ti}-\mathrm{Mg} / \mathrm{Si}$ thin films

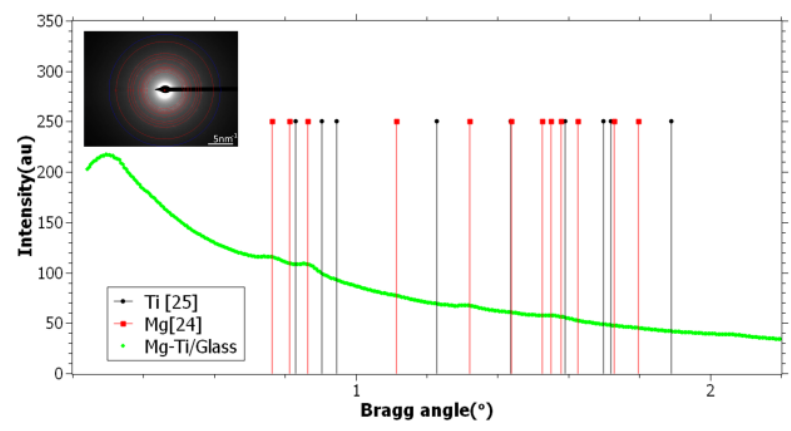

Figure 6 RDF functions extracted by means of CRISP2 ELD module for $\mathrm{Ti}-\mathrm{Mg} / \mathrm{Gl}$ thin films

Electron diffraction of samples exhibit a polycrystalline character. Using comparative method [28,29], weak peak was indexing and Miller indices was used to evaluate lattice parameters. We obtain the values show in table 2 below, that show lattice parameters calculated directly from interplanar distance using,

$\frac{1}{d_{h k l}^{2}}=\frac{4}{3}\left(\frac{h^{2}+h k+k^{2}}{a_{0}^{2}}\right)+\frac{l^{2}}{c_{0}^{2}}$

and Cohen method. In first case lattice parameters was calculated as mean of values obtained from d-values with $\mathrm{l}=0$, for $\mathrm{a}$, and with $\mathrm{h}=\mathrm{k}=0$, for $\mathrm{c}$. For Cohen method only $\mathrm{Mg}$ phase (indexed peak) was considered.

Table 2. Network parameters using the Cohen method.

\begin{tabular}{|c|c|c|}
\hline \multirow[t]{2}{*}{ Sample } & Ti-Mg/Si & Ti-Mg/Gl \\
\hline & \multicolumn{2}{|c|}{$\begin{array}{l}\text { Hexagonal crystalline structure } \\
(\mathrm{Mg}, \mathrm{Ti})\end{array}$} \\
\hline $\begin{array}{c}\text { Network } \\
\text { parameters } \\
{[1]}\end{array}$ & $\begin{array}{c}\mathrm{Mg} \\
\mathrm{a}_{0}=3,1874 \AA \\
\mathrm{c}_{0}=5,0595 \AA \\
\mathrm{Ti} \\
\mathrm{a}_{0}=3,0002 \AA \\
\mathrm{c}_{0}=4,5561 \AA\end{array}$ & $\begin{array}{c}\mathrm{Mg} \\
\mathrm{a}_{0}=3,285 \AA \\
\mathrm{c}_{0}=5,306 \AA \\
\mathrm{Ti} \\
\mathrm{a}_{0}=2,878 \AA \\
\mathrm{c}_{0}=4,486 \AA\end{array}$ \\
\hline $\begin{array}{c}\text { Relative } \\
\text { errors }(\%) \\
{[2]}\end{array}$ & $\begin{array}{c}\mathrm{Mg} \\
0,69 \%, 2,9 \% \\
\mathrm{Ti} \\
1,70 \%, 2,77 \%\end{array}$ & $\begin{array}{c}\mathrm{Mg} \\
2,35 \%, 1,84 \% \\
\mathrm{Ti} \\
2,41 \%, 4,25 \%\end{array}$ \\
\hline
\end{tabular}


It can be seen that in the case of $\mathrm{Mg}$ the parameters are close to the values determined by other methods [Mg], instead of $\mathrm{Ti}$, the parameters are very high, due to the small number of identification lines for this phase.

From a morphological point of view, the $\mathrm{Ti}-\mathrm{Mg} / \mathrm{Gl}$ coatings are a polycrystalline materials, the DebyeScherrer analysis of the diffraction pattern showing a distribution of crystalline grains of approximately 5.63 $\mathrm{nm}$.

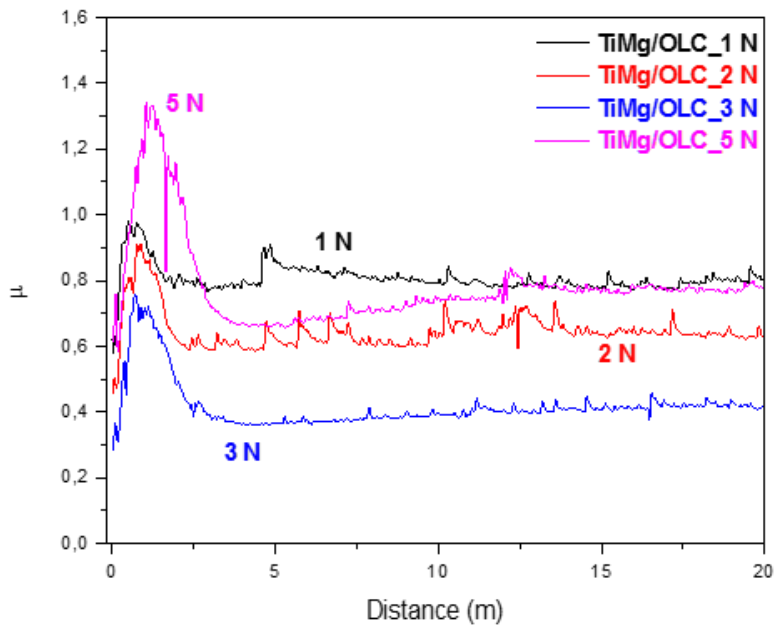

(a)

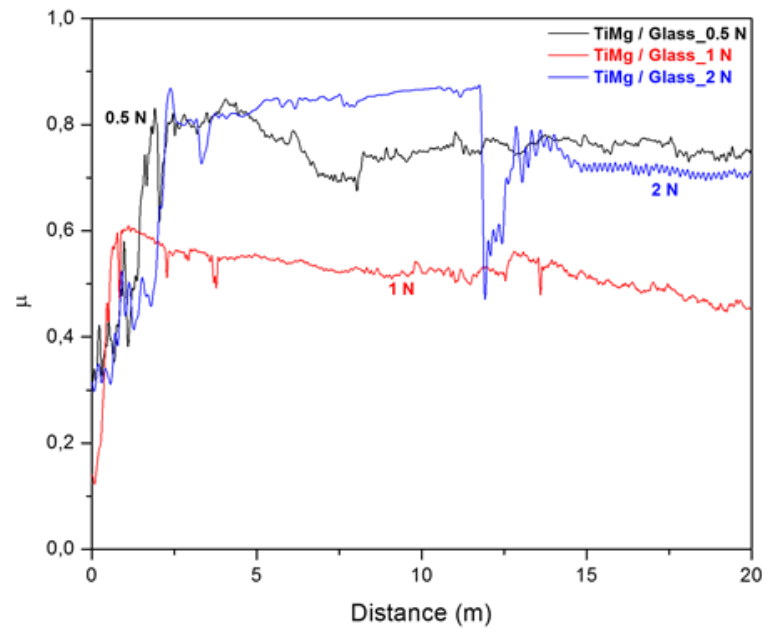

(b)

Figure 7 Friction coefficient for $\mathrm{Ti}-\mathrm{Mg} / \mathrm{OLC}$ and $\mathrm{Ti}-$ $\mathrm{Mg} / \mathrm{Gl}$ thin films

Tribological measurements for Ti-Mg deposited on OLC 45 substrate were performed using a ball-on-disc tribometer, with a normal force of $1 \mathrm{~N}, 2 \mathrm{~N}, 3 \mathrm{~N}$ and $5 \mathrm{~N}$, respectively. In the case of $\mathrm{Ti}-\mathrm{Mg}$ deposited on glass substrate the measurements were achieved with a normal force of $0.5 \mathrm{~N}, 1 \mathrm{~N}$ and $2 \mathrm{~N}$, respectively. The stainless steel ball has a diameter of $6 \mathrm{~mm}$, a dry sliding distance of $20 \mathrm{~m}$, and a linear speed of $2 \mathrm{~cm} / \mathrm{s}$. Figure 7 shows a comparative view of the friction coefficient for $\mathrm{Ti}-\mathrm{Mg}$ films deposited on the OLC 45 and glass substrate at different loading forces. An increasing tendency of the friction coefficient with the increase of the applied force was noticed for Ti-Mg thin films.

\section{Conclusions}

Thermionic Vacuum Arc technology can be used successfully for Ti-Mg coatings deposition, providing superior qualities and high purity. The nanocomposites were investigated using Transmission Electron Microscopy (TEM) analyses provided with HR-TEM and SAED facilities. For Ti-Mg samples the amorphous phase, respectively hexagonal $\mathrm{Mg}$ and less problable $\mathrm{Ti}$ hexagonal could be identified. It can be said that there is an unequal percentage, the hexagonal $\mathrm{Mg}$ phase being predominant, and there is also the possibility of a relatively small percentage of cubic $\mathrm{MgO}$. Selected area electron diffraction (SAED) technique provided the crystalline characteristics of the titanium in magnesium matrix. Characterization with Scanning Electron Microscopy (SEM) revealed that the particle size of the nanoparticles composing the Ti-Mg thin films on different substrates is in the nanometer scale and confirmed the calculated value of particle size from Debye Scherrer's formula. Tribological measurements show an increasing tendency of the friction coefficient with the increase of the applied force, especially in the case of the film deposited on the glass.

The finding that the grain size distributions are different in Ti-Mg deposited on different substrates and depend on the growth conditions is important and must be taken into account in the search of the optimal composition to improve the coating properties of these materials for industrial applications

\section{Acknowledgment}

This work was supported by a grant of Ministry of Research and Innovation, CNDI-UEFISCDI, project 70/2017, PN-III-P4-ID-PCE-2016-0750 within PNCDI III

\section{References}

1. P. Zhang, B.K. Tay, C.Q. Sun and S.P. Lau 2002 J Vac Sci Technol A 20 1390-1394

2. Y. Pauleau and F. Thiery 2004 Surf. Coa.t Technol 180-181 313-322

3. A. Y. Wang, K. R. Lee, J. P. Ahn and J. H. Han 2006 Carbon 441826.

4. Li C, Wu Y, Li H and Liu X 2009 J. Alloys Compd. 477212

5. Baleva M, Zlateva G, Atanassov A, Abrashev M and Goranova E 2005 Phys. Rev. B 72115330

6. Tani J I and Kido H 2008 Intermetallics 16418

7. Hachiya K, Goto $\mathrm{T}$ and Hagiwara R 2007 Electrochim. Acta 5346

8. Zhao Y, Qin M J, Dou S X, Ionescu M and Munroe P 2006 J. Appl. Phys. 99 08M503

9. Saravanan R and Robert M C 2009 J. Alloys Compd. 47926 
10. Akasaka M, Lida T, Matsumoto A, Yamanaka K, Takanashi Y, Imai T and Hamada N 2008 J. Appl. Phys. 104013703

11. Nolas G S, Wang D and Beekman M 2007 Phys. Rev. B 76235204

12. Yong Liu, Kaiyang Li, Tao Luo, etl al. 2015 Materials Science and Engineering C 56 241-250

13. Junko Hieda, Mitsuo Niinomi, Masaaki Nakai, Ken Cho 2015 Materials Science and Engineering C 54 $1-7$

14. Guangyu Zhao, Li Zhang, Yanning Niu, Kening Sun 2017 Electrochimica Acta 224 64-70

15. Chong Lu, Jianxin Zou, et. al. 2016 International Journal Of Hydrogen Energy xxx 1-9

16. R. Vladoiu, V. Dinca, and G. Musa 2009 The European Physical Journal D 54 433-437

17. Vladoiu, R., Ciupina, V., Mandes, A., Dinca, V., Prodan, M., Musa, G. 2010 J. Appl. Phys. 108 093301

18. V. Ciupina, R. Vladoiu, C.P. Lungu, V. Dinca, M. Contulov, A. Mandes, P. Popov and G. Prodan, 2012 European Physical Journal D 6689

19. A. Mandes, R. Vladoiu, V. Dinca, G. Prodan 2014 IEEE TRANSACTIONS ON PLASMA SCIENCE $422806-2807$
20. R. Vladoiu, A Mandes, V D Balan, G. Prodan, P Kudrna, M. Tichy 2015 Plasma Sources Science \& Technology 24 35008-35008

21. R. Vladoiu, A. Mandes, V. Dinca, G. Prodan, V. Ciupina 2016 Romanian Reports In Physics 68 1076-1084

22. V.S. Teodorescu, M-G. Blanchin 2009 Microsc. Microanal. 515

23. (WWW-MINCRYST, SILICON-4221); Wyckoff R.W.G. $1963 *$ Crystal Structures, sec. ed. 1 26-27

24. (WWW-MINCRYST, MAGNESIUM-2671) Swanson and Tatge $1951 *$ JC Fel. Reports, NBS

25. (WWW-MINCRYST, TITANIUM-4770); Wyckoff R.W.G. 1963 * Crystal Structures 1 9-11;

26. (WWW-MINCRYST, PERICLASE-3533) ; Sasaki S., Fujino K., Takeuchi Y. 1979 * Proc. Jpn. Acad. 5543

27. (WWW-MINCRYST, ANATASE-190), Wyckoff R.W.G. $1963 *$ Crystal Structures 1 253-254;

28. B.D. Cullity, S. R. Stock 2001 3rd Edition, Prentice Hall, Upper Sadle River USA

29. J. B. Nelson, D. P. Riley 1945 Proc. Phys. Soc. 57 160-176, 